\title{
Anti-bacterial activity of Annona muricata Linnaeus extracts: a systematic review
}

\author{
Ricardo Mendes da SILVA ${ }^{1 *}$ (D), Isabella de Matos Mendes da SILVA ${ }^{1}$, Maria Manuela ESTEVINHO², \\ Leticia M. ESTEVINHO ${ }^{3}$
}

\begin{abstract}
Current analysis systematically reviews data available in the literature on the anti-bacterial activity of Annona muricata extracts (AME) against Staphylococcus aureus and Escherichia coli. Search was undertaken at four electronic databases and studies' quality were assessed. Results were summarized and Minimum Inhibitory Concentration (MIC) of AME (versus antimicrobial control) against $S$. aureus and E. coli was the main datum analyzed. The initial database search yielded 2,433 results. We selected 14 studies and four were used for meta-analysis. The MIC ranged between $156 \mu \mathrm{g} / \mathrm{mL}$ and $1,024 \mu \mathrm{g} / \mathrm{mL}$ against $S$. aureus and between $256 \mu \mathrm{g} / \mathrm{mL}$ and $1,024 \mu \mathrm{g} / \mathrm{mL}$ against $E$. coli. The different strains of $E$. coli studied were more sensitive to AME than those of $S$. aureus. The differences mean concentrations and standard deviations between AME and antimicrobials were 101.91 and 946.05 for E. coli, and 388.90 and 970.61 for S. aureus respectively. The heterogeneity of data is highlighted. Different methodologies were used, several studies didn't include antibiotics as control, antibiotics were different and various concentrations of extracts were tested. Studies showed possibilities of the plant under analysis as a source of new phytochemical compounds against microorganisms.
\end{abstract}

Keywords: soursop; anti-bacterial agents; plant extracts; antimicrobial resistance.

Practical Application: Development of phytotherapics and indication of a methodological script for research on antimicrobial action with plant extracts.

\section{Introduction}

It is common knowledge that novel pathogens resistance mechanisms against antimicrobials are emerging and spreading worldwide increasing bacterial resistance due to the dissemination of antibiotic resistance genes (ARGs) via plasmids and transposable elements between microbial communities, hindering the effectiveness of the treatment of common infectious diseases and causing prolonged illness, disability and death In recent years, antibiotic treatment for common infectious (Le et al., 2018; World Health Organization, 2019). Over-usage of antimicrobial agents in hospitals and by the community is a strong impetus for antimicrobial-resistant pathogens (Nagel et al., 2016).

Further, the use of antimicrobial agents in stockbreeding and agriculture contributes towards the selection of potentially resistant bacteria transferred to humans, directly or indirectly, through the food chain, representing a public health hazard (Lhermie et al., 2019). Indeed, sub-therapeutic antimicrobial concentrations may promote the development of acquired bacterial resistance by non-specific mutagenesis (Kohanski et al., 2010; Le et al., 2018).

The emergence and spread of antibiotic resistance and the evolution of new strains of pathogenic agents are a great concern to community health worldwide and entail the development of new antimicrobials or potential sources of novel drugs. Commonly used medicinal plants are promising sources of biologically active and safe compounds (Manandhar et al., 2019).

Plants are not merely chemically complex compounds, but their components may act synergistically on multiple targets. They may not only increase the efficacy but also minimize the possibility of resistance-developing pathogens (Wagner \& Ulrich-Merzenich, 2009). Over the last decades, various plant-derived compounds and their active principles have been analyzed for phytochemicals with anti-bacterial activity (Chowdaiah et al., 2019).

The genus Annona comprises over 70 species among which A. muricata is the most widely grown. A. muricata has been empirically employed in tropical regions to prevent and alleviate diverse ailments such as fever, pain, respiratory and skin diseases, parasites, bacterial infections, hypertension, inflammation, diabetes and cancer. In vitro studies have characterized A. muricata as a valuable antimicrobial, anti-inflammatory, anti-protozoan, anti-neoplastic and antioxidant agent (Coria-Téllez et al., 2018).

Studying methanolic extracts of A. muricata, Pinto et al. (2017) found antimicrobial activity in a broad spectrum of action, on bacterial membranes (both plasma and outer membranes, Gram positive and Gram negative) and Uchegbu et al. (2017) scanning antibacterial properties of $A$. muricata leaves ethanolic 
extracts, detected inhibition in all the tested organisms (S. aureus, P. mirabilis, K. pneumoniae, Salmonella and E. coli).

The present analysis systematically reviews the data available in the literature on the antibacterial activity of the extracts of A. muricata, regardless of the part of the plant and the solvent, against Gram positive (S. aureus) and Gram negative (E. coli), microorganisms most frequently found in our systematic review. Accessing current knowledge, following a reproducible methodology, this research aims to show gaps in the subject, review methodologies, stimulate new researches and induce faster practical applications.

\section{Material and methods}

\subsection{Search strategy}

Search on the literature was undertaken at four electronic databases (PubMed, Web of Science, ScienceDirect, and Scopus, following the Preferred Reporting Items for Systematic Reviews and Meta-Analyses [PRISMA] Guidelines, as recommended by Moher et al. (2009) and Higgins \& Green (2011). Search was carried out from inception to September 2019 using the following terms: [(“Annona muricata" OR graviola OR guanabana OR soursop) (extract* OR extrato OR Anti-bacterial OR antibacterian? OR Bacteria OR Antimicrobial OR antimicrobian?)]. No restriction on publication dates was applied and search included surveys in English, French, Portuguese and Spanish. Reference lists of the papers selected from the databases were manually reviewed to ensure that all pertinent articles were included.

\subsection{Eligibility and inclusion/exclusion criteria}

Only basic research articles were eligible for current systematic review. Inclusion criteria comprised i) studies on the anti-bacterial activity of Annona muricata L. extracts, and ii) studies on dilution in microplates and/or diffusion disc methods. Exclusion criteria comprised i) reviews; ii) studies which did not use A. muricata in microbiological tests, and iii) studies that did not use dilution in microplates and/or diffusion disc methods in their microbiological tests. Reviews and duplicates were excluded.

\subsection{Study selection and data collection process}

The studies identified through electronic or manual search were independently screened by two authors (RMS and IMMS). In the first phase, titles and abstracts were carefully analyzed. Whenever assessment clearly indicated that a particular study failed to meet the inclusion criteria, it was immediately excluded. In the second phase, for all the remaining potentially relevant studies, the full text was evaluated to determine its inclusion or exclusion. The lists of publications which met inclusion criteria were compared by each author and disagreements were discussed and consensus reached. The following information was collected from the selected studies: authors' names, publication year, country, impact factor, plant's origin, plant's material employed, voucher herbarium specimen (record of exsiccate deposit and taxonomic identification in an herbarium), antimicrobial susceptibility methods, microorganisms tested, antimicrobial used as control, use and identification of reference strains, extraction solvent type and concentration, re-dissolution solvent, mass volume ratio and major results obtained. Whereas one author completed the evidence table, the second author verified the data's accuracy. Results from each trial obtained by different methods (DDT and MAST) using the same microorganism (S. aureus and $E$. coli) were combined and polled together. The authors carefully confirmed that no statistical differences were observed between the combined groups, for each study.

\subsection{Quality assessment}

The quality of the included studies was independently assessed by two investigators, after adapting quality assessment tool [QATSDD] described by Sirriyeh et al. (2012). In the case of basic science, contrastingly to clinical studies, checklists and scores are rare to evaluate prior literature within a rigorous and quantitative manner. Therefore, the QATSDD scale was adapted to research aims by the authors. The developed tool included 13 items, scored from 0 to 3 , which reflected, among others, the definition of the issue, the identification of purpose and hypothesis, the study design, the quality of the methodology for data collection, data analysis and manuscript drafting. For each paper, the sum of the scores of all items was divided by maximum score (39 points) to obtain the paper's overall quality score.

\subsection{Statistical analysis}

Minimum Inhibitory Concentration (MIC) of A. muricata extracts (versus antimicrobial control) against $S$. aureus and $E$. coli was the main datum analyzed. The microorganisms were chosen since they had been evaluated in most studies and are important representatives of Gram positive and Gram negative groups. Data were extracted from each study and descriptive statistics (mean and standard deviation) were calculated. The two groups (extract and control) were then compared to evaluate the difference between mean MIC rate obtained for A. muricata extracts against $E$. coli and $S$. aureus strains when compared to control (conventional antimicrobial agent). This last analysis was performed in only four studies (Yasunaka et al., 2005, Bento et al., 2013, Dzotam et al., 2016; Pinto et al., 2017). Other studies were very heterogeneous and could not be quantitatively pooled.

\section{Results}

\subsection{Bibliographic search and study selection}

The initial electronic database search yielded 2,433 results (552 studies identified in PubMed; 853 in ScienceDirect; 520 in SCOPUS; 508 in Web of Science) as shown in Figure 1.

The manual bibliographic search did not retrieve any additional study. Moreover, 2,392 studies were excluded, including duplicates $(n=23)$ and 25 out of 41 texts fully analyzed were excluded since they failed to employ MAST or DDT methodologies and two did not employ A. muricata. In all, 14 studies were selected for inclusion in current systematic review.

\subsection{Description of the 14 publications selected}

Supplementary Table 1 provides an overview of the key characteristics of the 14 publications available as full texts. The studies were published between 2005 and 2019, with the largest number of articles $(\mathrm{n}=3)$ published in 2017 (Aruan et al., 


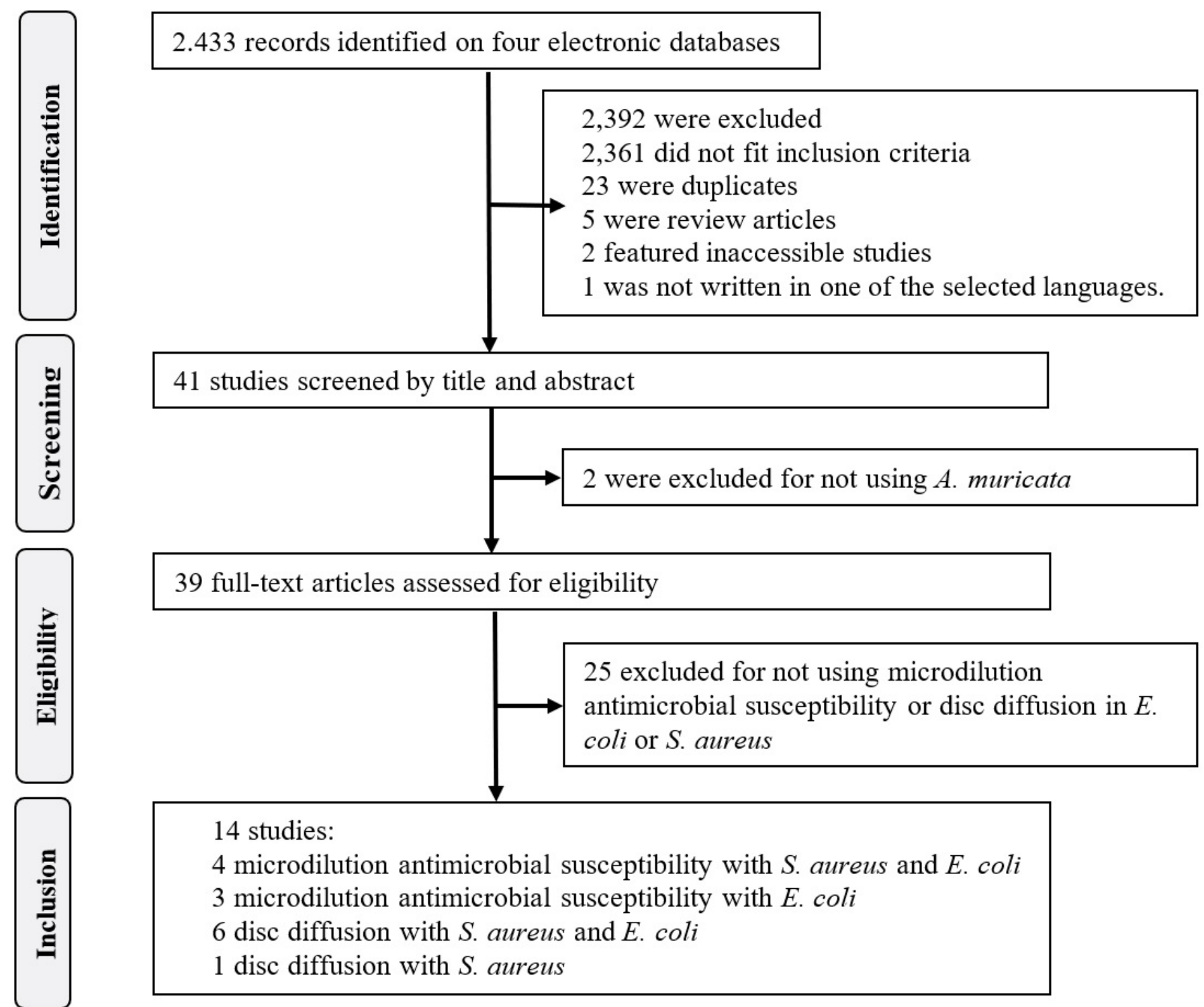

Figure 1. Flow diagram of current study's selection.

2017; Pinto et al., 2017; Ezealisiji et al., 2017) and in 2019 (Andrade et al., 2019; Nugraha et al., 2019; Sebastiammal et al., 2019). Most experiments (64.29\%) were performed with only A. muricata extracts (Aruan et al., 2017; Bento et al., 2013; Andrade et al., 2019; Pinto et al., 2017; Ezealisiji et al., 2017; Haro et al., 2014; Nugraha et al., 2019; Sánchez-Navarro et al., 2018; Sebastiammal et al., 2019). Most of the tested plants (35.71\%) hailed from Brazil (Bento et al., 2013; Andrade et al., 2019; Pinto et al., 2017; Takahashi et al., 2006; Viera et al., 2010).

The leaf was the most studied morphological part of the plant, featuring in eight studies (Aruan et al., 2017; Bento et al., 2013; Andrade et al., 2019; Pinto et al., 2017; Dzotam et al., 2016; Haro et al., 2014; Sánchez-Navarro et al., 2018; Takahashi et al., 2006) and root was the second most evaluated part (Nugraha et al., 2019 and Ezealisiji et al., 2017).

Most studies $(n=8)$ reported voucher herbarium specimen and taxonomic identification of $A$. muricata (Bento et al., 2013;
Bussmann et al., 2010; Andrade et al., 2019; Pinto et al., 2017; Dzotam et al., 2016; Nugraha et al., 2019; Takahashi et al., 2006; Yasunaka et al., 2005).

Most authors employed methanol and ethanol as extraction solvents ( $n=5$, each) as a methodology for extract preparation. Ethanol was used by Pinto et al. (2017), Dzotam et al. (2016), Haro et al. (2014), Nugraha et al. (2019) and Yasunaka et al. (2005) and methanol was used by Aruan et al. (2017), Bento et al. (2013), Bussmann et al. (2010), Viera et al. (2010) and Takahashi et al. (2006) Fifty percent of the studies revealed the concentration of extraction solvent (Bento et al., 2013; Pinto et al., 2017; Ezealisiji et al., 2017; Sánchez-Navarro et al., 2018; Sebastiammal et al., 2019; Takahashi et al., 2006; Yasunaka et al., 2005), of which $100 \%$ was the most prevalent (35.71\%) (Andrade et al., 2019; Dzotam et al., 2016; Haro et al., 2014; Nugraha et al., 2019; Viera et al., 2010). The mass/volume ratio for extraction was not reported in $57.14 \%$ of the studies 
(Aruan et al., 2017; Bento et al., 2013; Ezealisiji et al., 2017; Haro et al., 2014; Sánchez- Navarro et al., 2018; Sebastiammal et al., 2019; Takahashi et al., 2006; Yasunaka et al., 2005). Among the selected studies, 57.14\% used the MAST method (Bento et al., 2013; Bussmann et al., 2010; Andrade et al., 2019; Pinto et al., 2017; Dzotam et al., 2016; Nugraha et al., 2019; Sánchez-Navarro et al., 2018; Yasunaka et al., 2005), whilst $42.86 \%$ used the DDT method (Aruan et al., 2017; Ezealisiji et al., 2017; Haro et al., 2014; Sebastiammal et al., 2019; Takahashi et al., 2006; Viera et al., 2010). S. aureus was the most tested Gram positive bacterium (92.86\%) (Aruan et al., 2017; Bento et al., 2013; Bussmann et al., 2010; Andrade et al., 2019; Pinto et al., 2017; Ezealisiji et al., 2017; Haro et al., 2014; Nugraha et al., 2019; Sánchez-Navarro et al., 2018; Sebastiammal et al., 2019; Takahashi et al., 2006; Viera et al., 2010; Yasunaka et al., 2005). On the other hand, E. coli was the most tested Gram negative bacterium (85.71\%) (Bento et al., 2013; Andrade et al., 2019; Pinto et al., 2017; Dzotam et al., 2016; Ezealisiji et al., 2017; Haro et al., 2014; Nugraha et al., 2019; Sánchez-Navarro et al., 2018; Sebastiammal et al., 2019; Takahashi et al., 2006; Viera et al., 2010; Yasunaka et al., 2005). Reference strains were not employed in $21.43 \%$ of the tests (Aruan et al., 2017; Ezealisiji et al., 2017; Nugraha et al., 2019; Sebastiammal et al., 2019). The most used reference strain of S. aureus was ATCC25923 ( $\mathrm{n}=4$ ) (Bussmann et al., 2010; Andrade et al., 2019; Viera et al., 2010; Takahashi et al., 2006) and the most used reference strain of $E$. coli was ATCC25922 $(n=5)$ (Andrade et al., 2019; Haro et al., 2014; Nugraha et al., 2019; Sánchez-Navarro et al., 2018; Takahashi et al., 2006).

Bacteria were tested against commercial antimicrobial agents in $57.14 \%$ of the studies (Bento et al., 2013; Bussmann et al., 2010; Pinto et al., 2017; Dzotam et al., 2016; Ezealisiji et al., 2017; Sánchez-Navarro et al., 2018; Takahashi et al., 2006; Yasunaka et al., 2005).

The Impact Factor (IF) provided by the Journal Citation Reports (JCR) was absent in $21.43 \%$ of the articles (Aruan et al., 2017; Haro et al., 2014; Viera et al., 2010) and in 14.29\%, according to SCOPUS (Bento et al., 2013; Haro et al., 2014). The JCR Impact Factor ranged between 1.40 (Bento et al., 2013) and 24.37 (Sebastiammal et al., 2019), and in SCOPUS between 1.04 (Aruan et al., 2017) and 4.58 (Pinto et al., 2017).

The last column of the Supplementary Table 1 lists the methodological quality scores of the publications, whilst Supplementary Table 2 presents classifications attributed to each quality criteria. Scores ranged between $27.00 \%$ and $77.00 \%$, with a mean $54.29 \pm 15.42 \%$ [ \pm standard deviation]. In general, highest scores were obtained for items "accessible and transparent presentation of data throughout the paper" and "presentation, justification and relevance of the research problem" and the lowest for "statistical assessment of reliability and validity of measurement tools" and "draw consistent conclusions based on the evidence presented in the paper.

\subsection{Antimicrobial activity - synthesis of results}

In the case of MAST, the MIC ranged between 132 (Nugraha et al., 2019) and 128,000 $\mu \mathrm{g} / \mathrm{mL}$ (Bussmann et al., 2010) for S. aureus and between 132 (Nugraha et al., 2019) and
1,024 $\mu \mathrm{g} / \mathrm{mL}$ for E. coli (Bento et al., 2013; Dzotam et al., 2016; Yasunaka et al., 2005). The inhibition of halo growth in the analyzed publications which performed DDT ranged between 0.0 (Takahashi et al., 2006) and $14.0 \mathrm{~mm}$ (Viera et al., 2010) for S. aureus, and between 0.0 (Ezealisiji et al., 2017; Takahashi et al., 2006) and $8.0 \mathrm{~mm}$ (Haro et al., 2014) for E. coli.

Four out of the 14 publications were used for meta-analysis (Bento et al., 2013; Pinto et al., 2017; Dzotam et al., 2016; Yasunaka et al., 2005). The four studies tested the antibacterial activity of $A$. muricata extracts and it was compared with commercial antimicrobials against $E$. coli and $S$. aureus strains by using the MAST method. In studies for meta-analysis, 17 tests, or rather, six for S. aureus and 11 for E. coli, were performed. Dzotam et al. (2016) only tested E. coli, while the other three articles analyzed $E$. coli and $S$. aureus.

Bento et al. (2013) tested four commercial antimicrobial agents against $S$. aureus and E. coli and reported that the activity of $A$. muricata extract in three tests was more effective than antimicrobials, or rather, better than kanamycin against E. coli and $S$. aureus $(1,024 \mu \mathrm{g} / \mathrm{mL}$ extract concentration when compared to $2,500 \mu \mathrm{g} / \mathrm{mL}$ kanamycin concentration against the two bacteria), and better than gentamicin against $S$. aureus $(1.024 \mu \mathrm{g} / \mathrm{mL}$ extract concentration when compared to $2,500 \mu \mathrm{g} / \mathrm{mL}$ gentamicin concentration).

However, commercial antimicrobial agents performed better in 14 tests conducted by Bento et al. (2013), Pinto et al. (2017), Dzotam et al. (2016) and Yasunaka et al. (2005). Amikacin, neomycin, tetracycline and chloramphenicol performed better against $S$. aureus and $E$. coli than $A$. muricata extracts, while gentamicin performed better than A. muricata extracts only against $E$. coli.

Figure 2 gives the difference between mean MIC rate obtained for the different antimicrobial agents and $A$. muricata extracts against $E$. coli and $S$. aureus strains. The activity of $A$. muricata extracts was closer to the commercial antimicrobial agents against $E$. coli than against $S$. aureus. The MIC ranged between $156 \mu \mathrm{g} / \mathrm{mL}$ to $1,024 \mu \mathrm{g} / \mathrm{mL}$ against $S$. aureus and from $256 \mu \mathrm{g} / \mathrm{mL}$ to $1,024 \mu \mathrm{g} / \mathrm{mL}$ against E. coli. Mean 101.91 and standard deviation 946.05 for E. coli were lower than data obtained when comparing the activity of extracts with commercial antimicrobial agents challenged by S. aureus, 388.90 and 970.61 , mean and standard deviation, respectively.

\section{Discussion}

Interest in the biological properties of $A$. muricata has increased in recent years. There are currently several reports on the anticancer, anticonvulsant, anti-arthritic, anti-parasite, antimalarial, hepato-protective and anti-diabetic activities of $A$. muricata (Adewole \& Caxton-Martins, 2006; Sousa et al., 2010; Moghadamtousi et al., 2015). Several studies have been developed on the evaluation of antimicrobial activity, albeit with a limited number of samples. Therefore, results from existing studies were combined to increase their statistical capacity.

Brazil was the country of origin of most of the tested plants, probably because the graviola soursop is the second Annonaceae 




Figure 2. Difference between Minimum Inhibitory Concentration mean rates obtained for different antibiotics and Annona muricata L extracts against Escherichia coli and Staphylococcus aureus strains. Overall estimation (mean \pm standard deviation) is given on the right side.

in the Brazilian cultivated area, superseded only by sugar-apple, mainly in the northern region (Lemos, 2014).

The information about exsiccate deposit and taxonomic identification in a herbarium is very important and ensures that the researcher is working with the correct species (Peixoto \& Maia, 2013).

Regarding the methodology for the preparation of the extract, most authors used methanol and ethanol (35.71\%) as extraction solvents ( $\mathrm{n}=5$ each) currently used in the research of natural products, capable of extracting many phytochemicals. The use of non-aqueous solvent, such as dimethylsulfoxide (DMSO) is recommended by the Clinical and Laboratory Standards Institute (CLSI, formerly the National Committee for Clinical Laboratory Standards, NCCLS), because several compounds must be dissolved in solvents other than water. A series of dilutions with this solvent has been recommended for its preparation. Such procedure prevents artifacts resulting from the precipitation of products of low solubility in the aqueous medium (National Committee for Clinical Laboratory Standards, 2002).

Several different classes of metabolites were reported to exist in the extract of $A$. muricata, including tannins, alkaloids, flavonoids, polyphenols, saponins, diterpenoids, kaempferol and acetogenin compounds (Yang et al., 2015; George et al., 2015; Matsushige et al., 2012). The extract also contains triglycosides, megastigmans and more than 100 annonaceous acetogenin compounds (Moghadamtousi et al., 2015).

The extraction solvent concentration was reported only in one half of the studies. Further, lack of information on mass/volume ratio for extraction and re-dissolution solvent decreases the reproducibility of the research, highlighting the 
need to increase scientific protocols when reporting results in basic science studies.

Most studies used the MAST method rather than DDT. Determination of MIC is more specific than growth inhibition halo, because same sample is tested at different concentrations. According to Klančnik et al. (2010), the disk diffusion method was appropriate only as a preliminary screening test prior to MIC determination with the dilution method.

S. aureus and E. coli were the most tested microorganisms. Chai et al. (2019) analyzed the incubation periods of enteric diseases in foodborne outbreaks in the United States from 1998 to 2013 and reported that S. aureus and Shiga-toxin producing E. coli were reported in 153 and 178 outbreaks, respectively, on the top of the list of five etiologic agents of Foodborne Disease outbreak. Further, methicillin-resistant S. aureus (MRSA) is an important healthcare-associated pathogen causing illnesses ranging from localized skin infections to systemic diseases, including toxic shock syndrome (Neyra et al., 2014; Nugraha et al., 2019).

Most studies used reference strains (71.4\%) since they were actually the most efficacious for the quality control of dilution methods, with MIC rates close to mid-concentration range for all agents tested (National Committee for Clinical Laboratory Standards, 2016), allowing comparison between strains of clinical origin.

Moreover, $57.1 \%$ of publications analyzed used commercial antimicrobials, particularly chloramphenicol, for comparison with extract's activities. Klančnik et al. (2010) observed that there is no standard procedure for comparing commercial antimicrobials.

Synergism, a positive interaction between two compounds, is one manner by which plant-derived compounds exert their antibiotic potential (Silva et al., 2019). For instance, Pinto et al. (2017) reported on the synergic action of A. muricata extract particularly interfering with the stability of cellular membranes that facilitates the activities of antimicrobial agents. Further, Bento et al. (2013) investigated the association between the ethanol extract of A. muricata and four antimicrobial agents (gentamicin, kanamycin, amikacin and neomycin) and reported that, in all cases, there was a reduction in MIC when compared to antimicrobial agents acting alone within the $75.0-99.9 \%$ range.

In other natural matrixes, Enemchukwu et al. (2019) studied Vernonia amygdalina, Garcinia kola, tetracycline and metronidazole and combinations and found that synergic activity exists against diarrheagenic bacteria. Mancarz et al. (2019) studied a synergic interaction of two extracts from Liquidambar styraciflua with ciprofloxacin and tetracycline and a synergistic interaction was observed against the gram-positive bacterial Enterococcus faecalis (ATCC 29212) and S. aureus (ATCC 2592).

In current systematic review, four articles reported the use of green nanotechnology. Ezealisiji et al. (2017) and Sánchez-Navarro et al. (2018) used silver as nanocarrier; Sebastiammal et al. (2019) used CeO2, and Aruan et al. (2017) employed polyvinyl with alcohol/soursop leaves extract to synthetize nanofibers and evaluate their potential as anti-bacterial wound dressing. This demonstrates the long path to explore the full potential of nanotechnology associated with A. muricata as an antimicrobial agent.

Drug delivery systems (DDS) are extensively studied and disseminated to improve the efficacy and administration of active pharmaceutical compounds (Anselmo \& Mitragotri 2014). However, second generation (2G) DDS, mostly featuring green nanotechnology, emerged between 1980 and 2010 . Third generation DDS (from 2010) will have to be much more advanced to overcome physiochemical and biological barriers through nontoxic excipients (Park, 2014). Current researches in the synthesis of nanoparticles (NPs) using plant extracts has opened a new era for the development of nontoxic methods for the preparation of NPs (Kanwar et al., 2019).

As far as it is known, this is the first systematic review on the anti-bacterial activities of A. muricata extracts. Bioprospection of tropical plants for antimicrobial activity is of growing interest as this evaluation may bring about novel active natural products to be used in chemotherapy and in the industry, such as food deterioration-retardant agents (Takahashi et al., 2006). Thus, a systematic review on the theme may summarize and disseminate research works to identify gaps, make recommendations for future research (Arksey \& O'Malley, 2005) and bring faster results in basic research for its use in the pharmaceutical industry.

Among the limitations of current study, the heterogeneity of data is highlighted. In fact, different methodologies were used, namely, several studies did not include antibiotics as control; antibiotics used were very different in different studies; various concentrations of extracts were tested. In addition, the lack of comparison with standard strains may have biased results because, without these comparisons, they may not be reliable since they would be based on the absence of knowledge on the behavior of these clinical microorganisms. Klančnik et al. (2010) also observed that several methods for the plant extract's MIC measurement are available.

Polled quantitative analysis has been employed to combine results from different studies and thus produce estimates that summarize all (Roever, 2017). This quantitative synthesis was influenced by the heterogeneity of the data, including differences in methodologies for assessing antibacterial activity and the lack of comparison with commercial antimicrobial agents in several studies. Indeed, only four articles tested the extracts of A. muricata and commercial antimicrobial agents against strains of E. coli and S. aureus using MAST (Yasunaka et al., 2005, Bento et al., 2013, Dzotam et al., 2016; Pinto et al., 2017). This fact alone makes it difficult to evaluate $A$. muricata extracts.

The development of systematic reviews and meta-analyses that provide data on therapeutic resources of plant biocompounds have to cope with difficulties related to the heterogeneity of results from research with methodological weaknesses that were also highlighted by Freitas et al. (2017) when they reviewed the use of medicinal plants in venous ulcers by Takooree et al. (2019) in their review on Piper nigrum L. and by Diefenbach et al. (2018) in their analysis on the effect of copaiba oil (Copaifera spp.) in oral pathogens.

Based on our findings and the difficulties reported by other authors, a flowchart on antimicrobial actions of plant extracts 


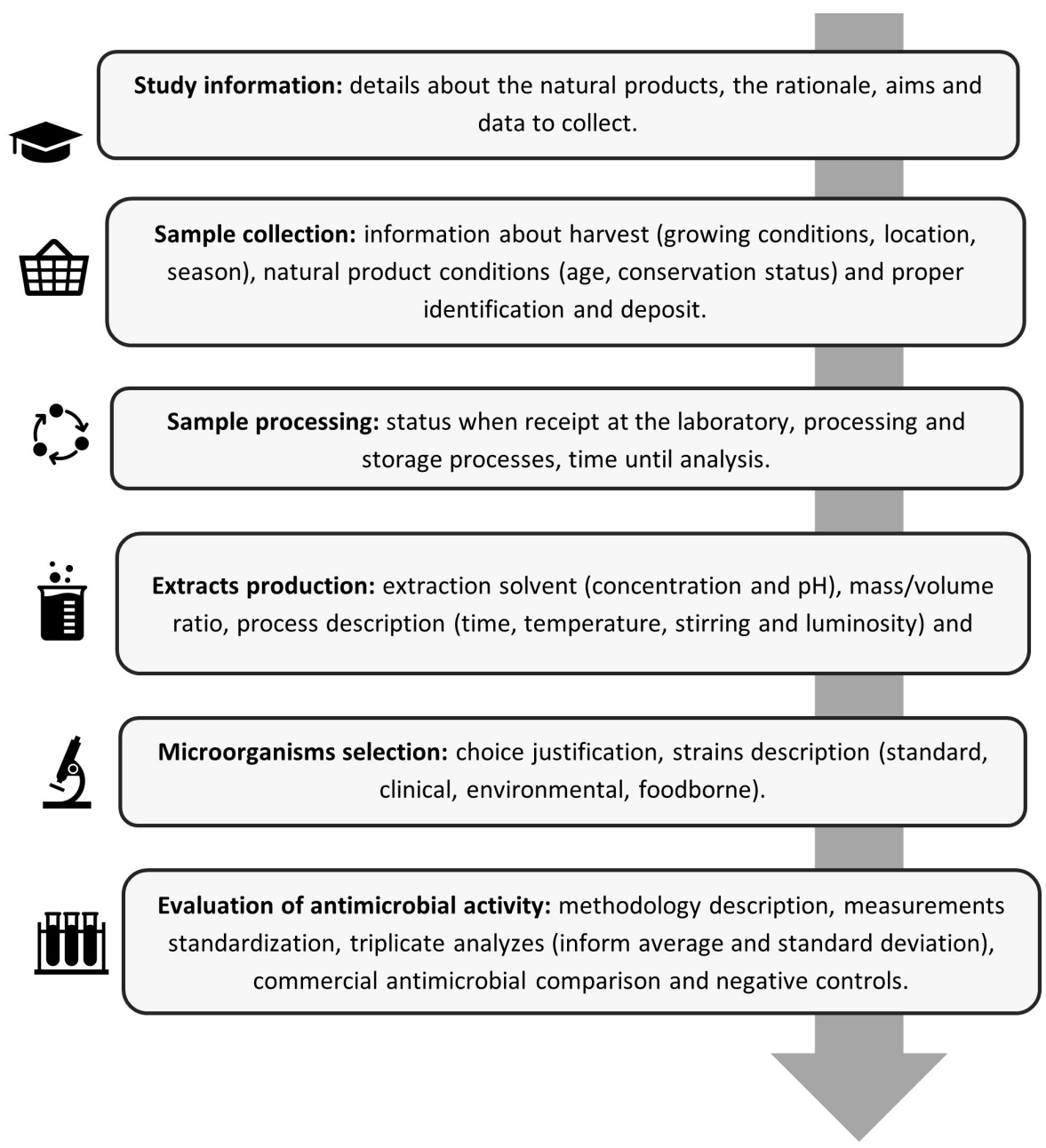

Figure 3. Research flowchart on antimicrobial action of natural products.

may be suggested which will help researchers to develop basic research in the area of biocompounds from vegetables (Figure 3). This flowchart includes (i) data collection; (ii) sample collection; (iii) sample processing; (iv) extracts production; (v) choice of microorganisms; (vi) evaluation of antimicrobial activities.

Although the methodology used in current analysis is commonly applied in clinical studies, its application in the setting of basic science is still fledging. It may, however, be a promising tool to increase statistical power and promote the translation of laboratory findings into practical applications.

\section{Conclusion}

The 14 publications selected for current study showed the several possibilities of the plant under analysis as a source of new phytochemicals against microorganisms. However, the study also recommended improvement of the methodological quality of the research on A. muricata extracts. Even though the antimicrobial action of $A$. muricata extracts was verified, the dispersion of results of articles with MAST was reported. Our findings may contribute to improve scientific standards and rigor of studies on this and other natural products, thereby increasing their reliability and importance while promoting the transition from basic to applied research.

In order to help in the production of new researches and accelerate the transition from basic research findings to therapeutic alternatives in human and veterinary medicine, the authors developed a research flowchart to guide future high-quality studies on the antimicrobial activity of natural products.

Further, besides the "isolated" study of phytochemicals, the assessment of the synergic action between the extract and commercial antimicrobial agents and the new possibilities of green nanotechnology is warranted, particularly taking into account the drug-resistance crisis that is expected in the future.

\section{References}

Adewole, S. O., \& Caxton-Martins, E. A. (2006). Morphological changes and hypoglycemic effects of Annona muricata Linn. (Annonaceae) leaf aqueous extract on pancreatic B-cells of streptozotocin-treated diabetic rats. African Journal of Biomedical Research, 9, 173-187.

Andrade, F. H. D., Batista, R. S. A., Lins, T. B., Fernandes, F. H. A., Brandão, D. O., Macedo, R. O., Souza, F. S., \& Wanderley, A. G. (2019). Thermal characterization and microbiology assay of Annona 
muricata L. leaves. Journal of Thermal Analysis and Calorimetry, 138(5), 3737-3745. http://dx.doi.org/10.1007/s10973-019-08050-w.

Anselmo, A. C., \& Mitragotri, S. (2014). An overview of clinical and commercial impact of drug delivery systems. Journal of Controlled Release, 190, 15-28. http://dx.doi.org/10.1016/j.jconrel.2014.03.053. PMid:24747160

Arksey, H., \& O'Malley, L. (2005). Scoping studies: towards a methodological framework. International Journal of Social Research Methodology, 8(1), 19-32. http://dx.doi.org/10.1080/1364557032000119616.

Aruan, N. M., Sriyanti, I., Edikresnha, D., Suciati, T., Munir, M. M., \& Khairurrijal, (2017). Polyvinyl alcohol/soursop leaves extract composite nanofibers synthesized using electrospinning technique and their potential as antibacterial wound dressing. Procedia Engineering, 170, 31-35. http://dx.doi.org/10.1016/j.proeng.2017.03.006.

Bento, E. B., Matias, E. F., Brito, F. E. Jr, Oliveira, D. R., Coutinho, H. D., Costa, J. G., Kerntopf, M. R., \& Menezes, I. R. A. (2013). Association between food and drugs: antimicrobial and synergistic activity of Annona muricata L. International Journal of Food Properties, 16(4), 738-744. http://dx.doi.org/10.1080/10942912.2011.565905.

Bussmann, R. W., Malca-García, G., Glenn, A., Sharon, D., Chait, G., Díaz, D., Pourmand, K., Jonat, B., Somogy, S., Guardado, G., Aguirre, C., Chan, R., Meyer, K., Kuhlman, A., Townesmith, A., Effio-Carbajal, J., Frías-Fernandez, F., \& Benito, M. (2010). Minimum inhibitory concentrations of medicinal plants used in Northern Peru as antibacterial remedies. Journal of Ethnopharmacology, 132(1), 101-108. http://dx.doi.org/10.1016/j.jep.2010.07.048. PMid:20678568.

Chai, S. J., Gu, W., O'Connor, K. A., Richardson, L. C., \& Tauxe, R. V. (2019). Incubation periods of enteric illnesses in foodborne outbreaks, United States, 1998-2013. Epidemiology and Infection, 147, e285. http://dx.doi.org/10.1017/S0950268819001651. PMid:31587689.

Chowdaiah, M., Sharma, P., \& Dhamodhar, P. (2019). A Study on phytochemicals from medicinal plants against multidrug resistant Streptococcus mutans. International Journal of Peptide Research and Therapeutics, 25(4), 1581-1593. http://dx.doi.org/10.1007/ s10989-018-09801-3.

Coria-Téllez, A. V., Montalvo-Gónzalez, E., Yahia, E. M., \& ObledoVázquez, E. N. (2018). Annona muricata: a comprehensive review on its traditional medicinal uses, phytochemicals, pharmacological activities, mechanisms of action and toxicity. Arabian Journal of Chemistry, 11(5), 662-691. http://dx.doi.org/10.1016/j.arabjc.2016.01.004.

Diefenbach, A. L., Muniz, F. W. M. G., Oballe, H. J. R., \& Rösing, C. K. (2018). Antimicrobial activity of copaiba oil (Copaifera ssp.) on oral pathogens: systematic review. Phytotherapy Research, 32(4), 586-596. http://dx.doi.org/10.1002/ptr.5992. PMid:29193389.

Dzotam, J. K., Touani, F. K., \& Kuete, V. (2016). Antibacterial activities of the methanol extracts of Canarium schweinfurthii and four other Cameroonian dietary plants against multi-drug resistant Gramnegative bacteria. Saudi Journal of Biological Sciences, 23(5), 565570. http://dx.doi.org/10.1016/j.sjbs.2015.06.006. PMid:27579004.

Enemchukwu, C. M., Oli, A. N., Okoye, E. I., Ujam, N. T., Osazuwa, E. O., Emechebe, G. O., Okeke, K. N., Ifezulike, C. C., Ejiofor, O. S., \& Okoyeh, J. N. (2019). Winning the war against multi-drug resistant diarrhoeagenic bacteria. Microorganisms, 7(7), 197. http://dx.doi. org/10.3390/microorganisms7070197. PMid:31295889.

Ezealisiji, K. M., Noundou, X. S., \& Ukwueze, S. E. (2017). Green synthesis and characterization of monodispersed silver nanoparticles using root bark aqueous extract of Annona muricata Linn and their antimicrobial activity. Applied Nanoscience, 7(8), 905-911. http:// dx.doi.org/10.1007/s13204-017-0632-5.

Freitas, A. L., Santos, C. A., Souza, C. A., Nunes, M. A., Antoniolli, Â. R., Silva, W. B., \& Silva, F. A. (2017). The use of medicinal plants in venous ulcers: a systematic review with meta-analysis. International Wound Journal, 14(6), 1019-1024. http://dx.doi.org/10.1111/ iwj.12751. PMid:28488305.

George, V. C., Kumar, D. N., Suresh, P. K., \& Kumar, R. A. (2015). Antioxidant, DNA protective efficacy and HPLC analysis of Annona muricata (soursop) extracts. Journal of Food Science and Technology, 52(4), 2328-2335. http://dx.doi.org/10.1007/s13197-014-1289-7. PMid:25829616.

Haro, G., Utami, N. P., \& Sitompul, E. (2014). Study of the antibacterial activities of soursop (Annona muricata L.) leaves. International Journal of Pharm Tech Research, 6(2), 575-581.

Higgins, J. P. T., \& Green, S. (2011). Cochrane Handbook for Systematic Reviews of Interventions Version 5.1.0. Oxford: The Cochrane Collaboration. Retrieved from http://handbook.cochrane.org.

Kanwar, R., Rathee, J., Salunke, D. B., \& Mehta, S. K. (2019). Green nanotechnology-driven drug delivery assemblies. ACS Omega, 4(5), 8804-8815. http://dx.doi.org/10.1021/acsomega.9b00304. PMid:31459969.

Klančnik, A., Piskernik, S., Jeršek, B., \& Možina, S. S. (2010). Evaluation of diffusion and dilution methods to determine the antibacterial activity of plant extracts. Journal of Microbiological Methods, 81(2), 121-126. http://dx.doi.org/10.1016/j.mimet.2010.02.004. PMid:20171250.

Kohanski, M. A., DePristo, M. A., \& Collins, J. J. (2010). Sublethal antibiotic treatment leads to multidrug resistance via radicalinduced mutagenesis. Molecular Cell, 37(3), 311-320. http://dx.doi. org/10.1016/j.molcel.2010.01.003. PMid:20159551.

Le, T. H., Ng, C., Tran, N. H., Chen, H., \& Gin, K. Y. H. (2018). Removal of antibiotic residues, antibiotic resistant bacteria and antibiotic resistance genes in municipal wastewater by membrane bioreactor systems. Water Research, 145, 498-508. http://dx.doi.org/10.1016/j. watres.2018.08.060. PMid:30193193.

Lemos, E. E. P. (2014). The production of annona fruits in Brazil Revista Brasileira de Fruticultura, 36(spe1), 77-85. http://dx.doi. org/10.1590/S0100-29452014000500009.

Lhermie, G., Wernli, D., Jørgensen, P. S., Kenkel, D., Lawell, C. Y. C. L., Tauer, L. W., \& Gröhn, Y. T. (2019). Tradeoffs between resistance to antimicrobials in public health and their use in agriculture: Moving towards sustainability assessment. Ecological Economics, 166, 106427. http://dx.doi.org/10.1016/j.ecolecon.2019.106427.

Manandhar, S., Luitel, S., \& Dahal, R. K. (2019). In vitro antimicrobial activity of some medicinal plants against human pathogenic bacteria. Journal of Tropical Medicine, 2019, 1895340. http://dx.doi. org/10.1155/2019/1895340. PMid:31065287.

Mancarz, G. F. F., Laba, L. C., Silva, E. C. P., Prado, M. R. M., Souza, L. M., Souza, D., Nakashima, T., \& Mello, R. G. (2019). Liquidambar styraciflua L.: a new potential source for therapeutic uses. Journal of Pharmaceutical and Biomedical Analysis, 174, 422-431. http:// dx.doi.org/10.1016/j.jpba.2019.06.003. PMid:31220700.

Matsushige, A., Kotake, Y., Matsunami, K., Otsuka, H., Ohta, S., \& Takeda, Y. (2012). Annonamine, a new aporphine alkaloid from the leaves of Annona muricata. Chemical \& Pharmaceutical Bulletin, 60(2), 257-259. http://dx.doi.org/10.1248/cpb.60.257. PMid:22293487.

Moghadamtousi, S. Z., Fadaeinasab, M., Nikzad, S., Mohan, G., Ali, H. M., \& Kadir, H. A. (2015). Annona muricata (Annonaceae): a review of its traditional uses, isolated acetogenins and biological activities. International Journal of Molecular Sciences, 16(7), 1562515658. http://dx.doi.org/10.3390/ijms160715625. PMid:26184167.

Moher, D., Liberati, A., Tetzlaff, J., \& Altman, D. G. (2009). Preferred reporting items for systematic reviews and meta-analyses: the PRISMA statement. Annals of Internal Medicine, 151(4), 264-269. 
http://dx.doi.org/10.7326/0003-4819-151-4-200908180-00135. PMid:19622511.

Nagel, J. L., Kaye, K. S., LaPlante, K. L., \& Pogue, J. M. (2016). Antimicrobial stewardship for the infection control practitioner. Infectious Disease Clinics, 30(3), 771-784. http://dx.doi.org/10.1016/j.idc.2016.04.012. PMid:27515147.

National Committee for Clinical Laboratory Standards - NCCLS. (2016). Standard M23 - Development of in vitro susceptibility testing criteria and quality control parameters (4th ed.). Wayne: NCCLS.

National Committee for Clinical Laboratory Standards - NCCLS. (2002). Approved Standard M27-A2 - Reference method for broth dilution antifungal susceptibility testing of yeasts (2nd ed.). Wayne: NCCLS.

Neyra, R. C., Frisancho, J. A., Rinsky, J. L., Resnick, C., Carroll, K. C., Rule, A. M., Ross, T., You, Y., Price, L. B., \& Silbergeld, E. K. (2014). Multidrug-resistant and methicillin-resistant Staphylococcus aureus (MRSA) in hog slaughter and processing plant workers and their community in North Carolina (USA). Environmental Health Perspectives, 122(5), 471-477. http://dx.doi.org/10.1289/ehp.1306741. PMid:24508836.

Nugraha, A. S., Haritakun, R., Lambert, J. M., Dillon, C. T., \& Keller, P. A. (2019). Alkaloids from the root of Indonesian Annona muricata L. Natural Product Research, 35(3), 481-489. http://dx.doi.org/10.1 080/14786419.2019.1638380. PMid:31282747.

Park, K. (2014). Controlled drug delivery systems: past forward and future back. Journal of Controlled Release, 190, 3-8. http://dx.doi. org/10.1016/j.jconrel.2014.03.054. PMid:24794901.

Peixoto, A. L., \& Maia, L. C. (2013). Manual de procedimentos para herbários. Recife: UFPE Editora Universitária. Retrieved from http:// inct.florabrasil.net/wp-content/uploads/2013/11/Manual_Herbario.pdf

Pinto, N. C. C., Campos, L. M., Evangelista, A. C. S., Lemos, A. S. O., Silva, T. P., Melo, R. C. N., Lourenço, C. C., Salvador, M. J., Apolônio, A. C. M., Scio, E., \& Fabri, R. L. (2017). Antimicrobial Annona muricata L.(soursop) extract targets the cell membranes of Grampositive and Gram-negative bacteria. Industrial Crops and Products, 107, 332-340. http://dx.doi.org/10.1016/j.indcrop.2017.05.054.

Roever, L. (2017). Compreendendo os estudos de revisão sistemática. Revista da Sociedade Brasileira de Clínica Médica, 15(2), 127-130.

Sánchez-Navarro, M. D. C., Ruiz-Torres, C. A., Niño-Martínez, N., Sánchez-Sánchez, R., Martínez-Castañón, G. A., DeAlba-Montero, I., \& Ruiz, F. (2018). Cytotoxic and bactericidal effect of silver nanoparticles obtained by green synthesis method using Annona muricata aqueous extract and functionalized with 5-fluorouracil. Bioinorganic Chemistry and Applications, 2018, 6506381. http:// dx.doi.org/10.1155/2018/6506381. PMid:30410535.

Sebastiammal, S., Mariappan, A., Neyvasagam, K., \& Fathima, A. L. (2019). Annona muricata inspired synthesis of $\mathrm{CeO} 2$ nanoparticles and their antimicrobial activity. Materials Today: Proceedings, 9, 627-632.

Silva, D. M., Costa, P. A., Ribon, A. O., Purgato, G. A., Gaspar, D. M., \& Diaz, M. A. (2019). Plant extracts display synergism with different classes of antibiotics. Anais da Academia Brasileira de Ciências, 91(2), e20180117. http://dx.doi.org/10.1590/0001-3765201920180117. PMid:31090789.

Sirriyeh, R., Lawton, R., Gardner, P., \& Armitage, G. (2012). Reviewing studies with diverse designs: the development and evaluation of a new tool. Journal of Evaluation in Clinical Practice, 18(4), 746-752. http://dx.doi.org/10.1111/j.1365-2753.2011.01662.x. PMid:21410846.

Sousa, O. V., Vieira, G. D.-V., Pinho, J. D. J. R., Yamamoto, C. H., \& Alves, M. S. (2010). Antinociceptive and anti-inflammatory activities of the ethanol extract of Annona muricata L. leaves in animal models. International Journal of Molecular Sciences, 11(5), 2067-2078. http:// dx.doi.org/10.3390/ijms11052067. PMid:20559502.

Takahashi, J. A., Pereira, C. R., Pimenta, L. P., Boaventura, M. A. D., \& Silva, L. G. E. (2006). Antibacterial activity of eight Brazilian Annonaceae plants. Natural Product Research, 20(1), 21-26. http:// dx.doi.org/10.1080/14786410412331280087. PMid:16286303.

Takooree, H., Aumeeruddy, M. Z., Rengasamy, K. R., Venugopala, K. N., Jeewon, R., Zengin, G., \& Mahomoodally, M. F. (2019). A systematic review on black pepper (Piper nigrum L.): from folk uses to pharmacological applications. Critical Reviews in Food Science and Nutrition, 59(Supp. 1), S210-S243. http://dx.doi.org/10.1080/ 10408398.2019.1565489. PMid:30740986.

Uchegbu, R. I., Ukpai, K. U., Iwu, I. C., \& Akalazu, J. N. (2017). Evaluation of the antimicrobial activity and chemical composition of the leaf extract of Annona muricata Linn (Soursop) grown in Eastern Nigeria. Archives of Current Research International, 7(1), 1-7. http://dx.doi.org/10.9734/ACRI/2017/31929.

Viera, G. H. F., Mourão, J. A., Ângelo, Â. M., Costa, R. A., \& Vieira, R. H. S. D. F. (2010). Antibacterial effect (in vitro) of Moringa oleifera and Annona muricata against Gram positive and Gram negative bacteria. Revista do Instituto de Medicina Tropical de São Paulo, 52(3), 129-132. http://dx.doi.org/10.1590/S0036-46652010000300003. PMid:20602021.

Wagner, H., \& Ulrich-Merzenich, G. (2009). Synergy research: approaching a new generation of phytopharmaceuticals. Phytomedicine, 16(2-3), 97-110. http://dx.doi.org/10.1016/j.phymed.2008.12.018. PMid:19211237.

World Health Organization - WHO. (2019). Antimicrobial resistance. Retrieved from https://www.who.int/news-room/fact-sheets/detail/ antimicrobial-resistance

Yang, C., Gundala, S. R., Mukkavilli, R., Vangala, S., Reid, M. D., \& Aneja, R. (2015). Synergistic interactions among flavonoids and acetogenins in Graviola (Annona muricata) leaves confer protection against prostate cancer. Carcinogenesis, 36(6), 656-665. http://dx.doi. org/10.1093/carcin/bgv046. PMid:25863125.

Yasunaka, K., Abe, F., Nagayama, A., Okabe, H., Lozada-Pérez, L., López-Villafranco, E., Muñiz, E. E., Aguilar, A., \& Reyes-Chilpa, R. (2005). Antibacterial activity of crude extracts from Mexican medicinal plants and purified coumarins and xanthones. Journal of Ethnopharmacology, 97(2), 293-299. http://dx.doi.org/10.1016/j. jep.2004.11.014. PMid:15707768. 


\section{Supplementary Material}

Supplementary material accompanies this paper.

Supplementary Table 1. Characteristics of selected studies on the antibacterial action of Annona muricata L extracts against Staphylococcus aureus and Escherichia coli strains.

Suplemmentary Table 2. Assessment of quality of sellected studies on the antibacterial action of Annona muricata L extracts against Staphylococcus aureus and Escherichia coli strains.

This material is available as part of the online article from http://www.scielo.br/cta 